\title{
Causes of Blindness and Visual Impairment in Nigeria: The Nigeria National Blindness and Visual Impairment Survey
}

\author{
Mobammed M. Abdull, ${ }^{1}$ Selvaraj Sivasubramaniam, ${ }^{2}$ Gudlavalleti V. S. Murthy, ${ }^{2}$ \\ Clare Gilbert, ${ }^{2}$ Tafida Abubakar, ${ }^{3}$ Christian Ezelum, ${ }^{4}$ and Mansur M. Rabiu, ${ }^{5}$ \\ on behalf of Nigeria National Blindness and Visual Impairment Study Group
}

Purpose. Determine causes of blindness and visual impairment among adults aged $\geq 40$ years.

Methods. Multistage, stratified, cluster random sampling with probability proportional to size procedures were used to identify a nationally representative sample of 15,027 persons $\geq 40$ years of age. Distance vision was measured with a reduced logMAR tumbling E-chart. Clinical examination included a basic eye examination of all subjects and a more detailed examination of those who had presenting vision $<6 / 12$ in either eye. Cause for vision loss was assigned to all subjects with presenting vision $<6 / 12$ in any eye.

Results. Of the 15,122 persons aged $\geq 40$ years who were enumerated, 13,599 (89.9\%) were examined. In $84 \%$, blindness was avoidable. Uncorrected refractive errors were responsible for $57.1 \%$ of moderate $(<6 / 18-6 / 60)$ visual impairment. Cataract $(43 \%)$ was the commonest cause of blindness $(<3 / 60)$. Prevalence of cataract-related blindness was 1.8\% (95\% CI: 1.57-2.05) and glaucoma-related blindness was $0.7 \%$ (95\% CI: 0.55-0.88). Increasing age was associated with increasing prevalence of all major blinding conditions. Females, illiterate persons, and residents in the North East geopolitical zone had significantly higher odds of cataract-induced blindness and severe visual impairment.

Conclusions. The high proportion of avoidable blindness, with half being attributable to cataract alone and uncorrected refractive errors being responsible for $57 \%$ of moderate visual impairment, means that appropriate and accessible refraction and surgical services need to be provided. If priority attention is not given, the number of blind and severely visually impaired adults in Nigeria will increase by $>40 \%$ over the next decade. (Invest Ophthalmol Vis Sci. 2009;50:4114-4120) DOI: 10.1167/iovs.09-3507

From the ${ }^{1}$ Specialist Hospital, Bauchi, Nigeria; the ${ }^{2}$ International Centre for Eye Health, London School of Hygiene and Tropical Medicine, London, United Kingdom; the ${ }^{3}$ Ministry of Health, Dutse, Jigawa State, Nigeria; the ${ }^{4}$ Ministry of Health, Awka, Anambra State, Nigeria; and the ${ }^{5}$ National Eye Centre, Kaduna, Nigeria.

Supported by Sightsavers International, Christian Blind Mission, and Vellux Stiftung.

Submitted for publication February 2, 2009; revised March 26, 2009; accepted June 25, 2009

Disclosure: M.M. Abdull, None; S. Sivasubramaniam, None; G.V.S. Murthy, None; C. Gilbert, None; T. Abubakar, None; C. Ezelum, None; M.M. Rabiu, None

The publication costs of this article were defrayed in part by page charge payment. This article must therefore be marked "advertisement" in accordance with 18 U.S.C. $\$ 1734$ solely to indicate this fact.

Corresponding author: Gudlavalleti V. S. Murthy, International Centre for Eye Health, London School of Hygiene and Tropical Medicine, Keppel Street, London WC1E7HT, UK; gvs.murthy@1shtm.ac.uk.
Tigeria has a population of 146.25 million (2008 census) 1 and is the most populous country on the African continent. ${ }^{1}$ The country ranks eighth among the 10 countries with the largest populations in the world. ${ }^{1}$ The United Nations Human Development Index ranks Nigeria at 154 among 179 countries (low human development), whereas the Human Poverty Index ranks it at 111 among 135 developing countries. ${ }^{2}$ Nigeria has an area of $923,768 \mathrm{~km}^{2}$, it has diverse climatic conditions ranging from equatorial in the south to tropical in the center and arid in the north, ${ }^{3}$ and it is inhabited by 250 different ethnic groups. There are six administrative zones, 36 States, and one Federal Capital Territory. ${ }^{3}$

Nigerians have a low life expectancy at birth ( 46.5 years) and the infant mortality rate is high at $95.7 / 1000$ live births (2008). ${ }^{1}$. The World Health Organization (WHO) categorizes Nigeria in a group of sub-Saharan countries in Africa, where the estimated prevalence of blindness among those aged $\geq 50$ years is one of the highest in the world at 9\%. ${ }^{4}$ However, available prevalence data from Nigeria come from a few small studies undertaken during the past two decades (Kyari F, et al. IOVS 2004; 45:ARVO E-Abstract 1065). ${ }^{5-12}$ Data on the prevalence and causes of blindness at a national level are essential for developing national policies and strategies at the country level for optimal utilization of available resources and prioritization of regions and areas for the elimination of avoidable blindness. Nigeria is a signatory to VISION2020 and has already drawn up a national plan for achieving its goals in line with the resolution of the 56th World Health Assembly. ${ }^{13}$ To bridge the evidence gap for planning, the Federal Government fully endorsed and supported the national survey on blindness and visual impairment conducted from 2005 to 2007 . The purpose of the survey was to determine the prevalence, causes, and magnitude of blindness in Nigeria. ${ }^{14}$ Prevalence data have already been published, ${ }^{15}$ and in this publication the causes of blindness and visual impairment in Nigeria are described.

\section{MethodS}

A detailed description of the methods used in the survey, has been published earlier. ${ }^{14}$

\section{Sample Size}

The sample size $(15,027)$ was calculated based on an assumed prevalence of blindness (presenting visual acuity [VA] of $<3 / 60$ in the better eye) of $5 \%$ among those aged $\geq 40$ years, an absolute precision of $0.5 \%$ (a $95 \%$ confidence interval $[\mathrm{CI}]$ ), a design effect of 1.75 , and a response rate of $85 \%$.

\section{Sampling Strategy}

Multistage stratified cluster random sampling, with probability proportional to size (PPS) procedures, was adopted. The sample covered all states. The more populous states had more clusters compared with the less populous states. Enumeration was undertaken until the target of 
50 adults was attained in each cluster. Enumerated individuals were asked to attend the survey clinical station, set up in the local community, the next day. Individuals unable to attend the clinic were examined in their homes.

\section{Ethics Approval}

Ethics approval was provided by the London School of Hygiene and Tropical Medicine and the Federal Government of Nigeria. The study adhered to the tenets of the Declaration of Helsinki. Written informed consent was obtained from all participants before they were examined. Eye examination and service facilities (including aphakic spectacles) were provided to all individuals, regardless of their consent to participate in the study.

\section{Definitions}

World Health Organization categories of vision loss were used to define blindness and severe visual impairment, ${ }^{16}$ allowing international comparisons to be made. ${ }^{17-19}$

Blindness: A presenting VA (with glasses for distance if normally worn or unaided if glasses for distance not worn) of $<3 / 60$ in the better eye.

Severe Visual Impairment (SVI): A presenting VA of $<6 / 60$ to $3 / 60$ in the better eye.

Moderate Visual Impairment (Mod VI): A presenting VA of $<6 / 18$ to $6 / 60$ in the better eye.

Mild Visual Impairment (Mild VI): A presenting VA of $<6 / 12$ to $6 / 18$ in the better eye.

Normal (N): A presenting VA of $\geq 6 / 12$ in the better eye.

\section{Clinical Examination}

Personal and demographic data collected during enumeration were verified by a trained interviewer. All participants underwent distance VA measurement with a reduced $\log$ MAR E-chart, ${ }^{20}$ which was used in earlier surveys in Bangladesh and Pakistan. ${ }^{17,18}$ Each eye was first tested separately and then vision was recorded with both eyes open. Based on presenting VA, individuals were either given a red card (VA $\leq 6 / 12$ in either eye) or a green card (VA better than 6/12 in both eyes). All participants had automated refraction (model ARKM-100; Takagi Seiko, Nagano, Japan) and A-scan biometry (Optikon 2000 Biometer; Bioline S.p.A, Rome, Italy) performed by a trained optometrist. Visual acuities were retested with best correction. All participants had a basic eye examination by an ophthalmologist. Red card recipients, and one in eight with a green card, were then examined in more detail, including applanation tonometry, gonioscopy, dilated funduscopy, and lens grading according to the WHO lens grading system. ${ }^{21}$

Initial training was undertaken over 2 weeks, and training sessions were repeated for each geopolitical zone (GPZ). A pilot study was conducted in each GPZ. Interobserver agreement studies were conducted among the ophthalmic nurses and the ophthalmologists periodically throughout the study. Data were collected over a 30-month period from January 2005 to July 2007. The core team (four ophthalmologists and two optometrists) remained constant over the 30 months, whereas other personnel were recruited locally for each GPZ.

\section{Identification of Causes of Vision Loss}

All individuals with a presenting visual acuity of $<6 / 12$ in either eye were assigned a cause for their vision loss. The survey ophthalmologists determined the cause(s) using the principles outlined in the WHO Prevention of Blindness Performa (Version III). ${ }^{21}$ The algorithm was as follows:

- All causes in each eye that contributed to vision loss alone were first identified (there could be more than one cause for each eye).

- If any ocular disease was secondary to another glaucoma (e.g., chorioretinitis secondary to onchocerciasis) secondary to a hyperma- ture lens, or amblyopia secondary to a refractive error, the primary cause was selected as the principal cause for the eye.

- In identifying one principal cause for each eye, a cause that was treatable and where the treatment would, in the ophthalmologist's opinion, improve the vision of the eye was given precedence over a cause that was not treatable.

- If a cause was preventable but not treatable, it was identified as the primary cause for the eye if the other causes were neither treatable nor preventable.

- If a cause was neither treatable nor preventable, the ophthalmologists used their clinical acumen to identify the principal cause for the eye. Therefore treatable and preventable causes were preferentially selected over unavoidable causes.

After this, the main cause in the right eye or left eye was chosen to represent the principal cause for the person. If the causes in the right and left eyes differed, the principal cause for the person was selected as the one that was more amenable to treatment, or, if not treatable, more amenable to prevention. For example, if the main cause for one eye was cataract and the cause in the fellow eye was optic atrophy, then cataract was identified as the principal cause for the person.

As per the WHO procedure, refractive error was considered more amenable to treatment than cataract. ${ }^{21}$ If refractive error and cataract coexisted in the same eye, cataract was selected as the main cause if the refractive correction did not improve VA to $\geq 6 / 18$.

Significant cataract was defined as grade $2 \mathrm{~B}$ or 3 according to the Mehra-Minassian grading scheme $\mathrm{e}^{22}$ and/or a score of 2 to 3 according to the WHO lens grading system. ${ }^{23}$ Significant refractive error (including from uncorrected, non-IOL cataract surgery or couching-uncorrected aphakia) was defined as a presenting visual acuity of $<6 / 18$ improving to $\geq 6 / 18$ after correction. Glaucoma was defined as a cup-to-disc ratio of $\geq 0.7$ and/or intraocular pressure of $\geq 21 \mathrm{~mm}$ of $\mathrm{Hg}$, with characteristic changes in the optic disc.

\section{Statistical Analysis}

A customized database was created (Access; Microsoft, Redmond, WA) and two trained data entry clerks entered the data. All data entered were verified twice. Quality assurance procedures included a random verification of filled forms in the field and at the project office. All data were transferred to the International Centre for Eye Health, where cleaning and analysis was done (Stata 10.0; Stata Corp., College Station, TX).

Conditions were classified as preventable, treatable (i.e., avoidable), or unavoidable. Cause-specific proportions of blindness and visual impairment were determined by age, sex, literacy, residence, and administrative area. Univariate and age/sex-adjusted logistic regression modeling was used to explore associations of the major causes.

Design effects due to cluster sampling were taken into account in the calculation of CIs for prevalence estimates and of odds ratios in the regression modeling.

The cause-specific magnitude of vision loss in Nigeria was estimated using age and sex standardized prevalence data for the 2008 population and the projected population for 2020 (U.S. Census International Database; IDB). ${ }^{1}$ We used U.S. Census (IDB) figures for these estimations for 2008 and 2020 , as this is the only source of population data with age and sex distributions.

\section{Results}

\section{Study Population}

In the study, 15,122 persons aged $\geq 40$ years were enumerated, and 13,599 (89.9\%) were examined. Response rates were similar across GPZs and ranged from $88.2 \%$ to $91.1 \%$. The mean age of those examined was $55.9 \pm 12.4$ (SD) years being significantly higher for the men $(56.7 \pm 12.5)$ than for the women $(55.2 \pm 12.2 ; P=0.001)$. However, the difference in mean age between the men $(51.3 \pm 11.2)$ and the women 
(51.6 \pm 10.8$)$ among nonresponders was not significant. More than half of those examined were female (54\%). The demographic characteristics of the enumerated and examined populations have been described earlier. ${ }^{15}$ A total of 3,138 (23.1\%) of the 13,591 respondents who had presenting VA recorded, had VA $<6 / 12$ in the better eye. Of these, 569 (4.2\%; 95\% CI: 3.8 -4.6) were blind (presenting VA, <20/400), 203 (1.5\%; 95\% CI: $1.3-1,7$ ) had SVI (presenting VA, <20/200-20/400), and a further 1,364 (10.0\%; 95\% CI: 9.4-10.7) had Mod VI (presenting VA, <20/60-20/200).

\section{Causes of Bilateral Blindness and Visual Impairment}

All but 9 of the 3138 individuals with presenting VA $<6 / 12$ in the better eye underwent a detailed examination to elicit the principal cause of visual impairment.

Uncorrected refractive errors were the commonest cause of mild and moderate VI (77.9\% and 57.1\%, respectively; Table 1). Cataract was the commonest cause of SVI and blindness, being responsible for $45.3 \%$ and $43.0 \%$, respectively.

Among the blind, $84 \%$ was due to avoidable causes. The avoidable proportion was higher among those with Mild or Mod VI (Table 1).

Age-related causes were responsible for $41 \%$ of Mild VI, $60.7 \%$ of Mod VI, $75.9 \%$ of SVI, and $73.2 \%$ of blindness. In $56.6 \%$ of Mild VI, $35.8 \%$ of Mod VI, $15.8 \%$ of SVI, and $11.1 \%$ of blindness, the underlying etiology was unknown. Measles, use of traditional eye medicines, and vitamin A deficiency were responsible for $3.7 \%$ of blindness. Trauma (1.1\%) and surgical procedures $(2.8 \%)$ were also identified as causing blindness. Toxoplasmosis was responsible for $0.9 \%$ of Mild and $0.7 \%$ of Mod VI. Trachoma was responsible for $4.2 \%$ of blindness and onchocerciasis for $1.1 \%$.

Among persons with corneal scarring $(n=45)$, infections not due to trachoma or onchocerciasis were responsible for 28.9\% $(n=13)$, whereas measles/vitamin A deficiency or use of traditional eye medicines was responsible for $26.7 \%$ ( $n=$
12). Trauma was the underlying cause in $11.1 \%(n=5)$ and surgical procedures in $6.7 \%(n=3)$. In a further $26.7 \%(n=$ 12), no underlying cause was determined.

The prevalence of cataract blindness was $1.8 \%$ (95\% CI: 1.57-2.05; Table 2). Glaucoma blindness was the second most prevalent condition (prevalence- 0.7\%; 95\% CI: 0.55-0.88). The prevalence of blindness due to uncorrected refractive errors, onchocerciasis, trachoma, and diabetic retinopathy were low (Table 2).

Associations between sociodemographic variables and the cause-specific prevalence of presenting vision $<6 / 60$ in the better eye (encompassing both SVI and blindness) in univariate analysis are shown in Table 3 . Increasing age was associated with increasing prevalence of most of the important causes, including cataract and glaucoma. Most cause-specific prevalence rates were higher among the women.

Participants living in rural areas had a higher prevalence of cataract and corneal disease than did those from urban areas. The prevalence of glaucoma and conditions like diabetic retinopathy, CMV, etc., which cause posterior segment disease was higher among urban residents.

Prevalence of cataract was lowest in the South West and highest in the North East. Participants who were illiterate had a higher prevalence of all cause-specific conditions.

\section{Adjusted Association Analyses}

Each decade increase in age was significantly associated with increasing prevalence of all the common causes (Table 4). There was an exponential increase of 3.3 times higher risk of presenting vision $<6 / 60$ in the better eye due to cataract with each decade of life compared with those aged 40 to 49 years. Females had nearly twice the risk of having VA $<6 / 60$ due to cataract compared with males. Poor literacy was also associated with a higher risk of vision loss from cataract and refractive errors. The prevalence of vision loss from cataract was significantly lower in the South West than in the remaining five GPZs.

Table 1. Principal Cause among Subjects with Bilateral Blindness or SVI, Mod VI, or Mild VI

\begin{tabular}{|c|c|c|c|c|}
\hline Principal Cause & $<6 / 12-6 / 18$ (Mild VI) & $<6 / 18-6 / 60(\operatorname{Mod} V I)$ & $<6 / 60-3 / 60$ (SVI) & $<3 / 60$ (Blind) \\
\hline \multicolumn{5}{|l|}{ Treatable } \\
\hline Refractive error* & $779(77.9)$ & $776(57.1)$ & $23(11.3)$ & $8(1.4)$ \\
\hline Cataract* $^{*}$ & $123(12.3)$ & $350(25.8)$ & $92(45.3)$ & $244(43.0)$ \\
\hline Uncorrected aphakia* & $12(1.2)$ & $40(2.9)$ & $32(15.8)$ & $48(8.4)$ \\
\hline $\mathrm{PCO}^{*}$ & $1(0.1)$ & $3(0.2)$ & $1(0.5)$ & $1(0.2)$ \\
\hline Glaucoma* & $10(1.0)$ & $28(2.1)$ & $8(3.9)$ & $95(16.7)$ \\
\hline Diabetic retinopathy* & $4(0.4)$ & $1(0.1)$ & $1(0.5)$ & $3(0.5)$ \\
\hline Pterygium & $4(0.4)$ & $13(1.0)$ & 0 & $3(0.5)$ \\
\hline Total treatable & $933(93.3)$ & $1211(89.2)$ & $157(77.3)$ & $402(70.8)$ \\
\hline \multicolumn{5}{|l|}{ Preventable } \\
\hline Trachoma & $6(0.6)$ & $12(0.9)$ & $2(1.0)$ & $24(4.2)$ \\
\hline Other corneal scars & $8(0.8)$ & $19(1.4)$ & $12(5.9)$ & $45(7.9)$ \\
\hline Onchocerciasis & $1(0.1)$ & $2(0.1)$ & 0 & $6(1.1)$ \\
\hline Total preventable & $15(1.5)$ & $33(2.4)$ & $14(6.9)$ & $75(13.2)$ \\
\hline Total avoidable & $948(94.8)$ & $1244(91.6)$ & $171(84.3)$ & $477(84.0)$ \\
\hline \multicolumn{5}{|l|}{ Unavoidable } \\
\hline Phthisis/absent globe & $3(0.3)$ & $4(0.3)$ & $1(0.5)$ & $13(2.3)$ \\
\hline Macular degeneration* & $10(1.0)$ & $32(2.4)$ & $8(3.9)$ & $10(1.8)$ \\
\hline Optic atrophy & $4(0.4)$ & $14(1.0)$ & $1(0.5)$ & $21(3.7)$ \\
\hline Other retina and posterior & & & & \\
\hline segment & $13(1.3)$ & $32(2.4)$ & $17(8.4)$ & $17(3.0)$ \\
\hline Others & 0 & $3(0.2)$ & 0 & $2(0.3)$ \\
\hline Total unavoidable & $30(3.0)$ & $85(6.3)$ & $27(13.3)$ & $63(11.1)$ \\
\hline Undetermined & $22(2.2)$ & $29(2.1)$ & $5(2.5)$ & $28(4.9)$ \\
\hline All blindness & $1000(100)$ & $1358(100)$ & $203(100)$ & $568(100)$ \\
\hline
\end{tabular}

Data are the number of subjects (percentage of total group).

* Age related. 
TABLE 2. Prevalence of Cause-Specific Blindness and SVI of Common Blinding Conditions

\begin{tabular}{|c|c|c|c|c|c|c|}
\hline Causes & Blind (n) & Prevalence (\%) & $95 \% \mathrm{CI}$ & SVI $(n)$ & Prevalence $(\%)$ & $95 \% \mathrm{CI}$ \\
\hline Cataract & 244 & 1.8 & $1.57-2.05$ & 92 & 0.68 & $0.55-0.84$ \\
\hline Glaucoma & 95 & 0.7 & $0.55-0.88$ & 8 & 0.06 & $0.03-0.12$ \\
\hline Uncorrected aphakia & 48 & 0.35 & $0.26-0.47$ & 32 & 0.24 & $0.16-0.34$ \\
\hline Cornea (excluding trachoma) & 45 & 0.33 & $0.24-0.46$ & 12 & 0.09 & $0.05-0.16$ \\
\hline Trachoma & 24 & 0.18 & $0.1-0.27$ & 2 & 0.01 & $0.004-0.06$ \\
\hline Optic atrophy & 21 & 0.15 & $0.1-0.24$ & 1 & 0.007 & $0.001-0.053$ \\
\hline Phthisis & 13 & 0.1 & $0.05-0.18$ & 1 & 0.007 & $0.001-0.053$ \\
\hline Macular degeneration & 10 & 0.07 & $0.035-0.15$ & 8 & 0.06 & $0.03-0.12$ \\
\hline Uncorrected refractive errors & 8 & 0.06 & $0.03-0.12$ & 23 & 0.17 & $0.11-0.27$ \\
\hline Onchocerciasis & 6 & 0.04 & $0.014-0.14$ & 0 & - & - \\
\hline Diabetic retinopathy & 3 & 0.02 & $0.007-0.07$ & 1 & 0.007 & $0.001-0.053$ \\
\hline
\end{tabular}

\section{Number of People with Vision Loss by Cause in 2008 and 2020}

The crude prevalence of presenting vision $<6 / 12$ to $6 / 18$ in the better eye was $17.36 \%$, whereas the crude prevalence of presenting vision $<6 / 60$ was $5.68 \%$. However, there was a wide variation in the age and sex distribution in the different GPZs of Nigeria. Therefore the standard population of Nigeria was used to standardize the prevalence rates for projecting the magnitude. ${ }^{1}$ After standardization, 3.6 million adults had vision $<6 / 12$ to $6 / 60$, whereas an additional 1.02 million aged $\geq 40$ years had presenting vision $<6 / 60$ in the better eye (Table 5 ). Refractive errors were responsible for 2.46 million adults with vision $<6 / 12$ to $6 / 60$, whereas cataract was responsible for 0.63 million. Cataract was responsible for 0.4 million of these cases, and glaucoma was responsible for a further 0.15 million. The number will increase by $40.7 \%$ to 1.4 million by 2020 , assuming that the prevalence of cataract blindness/SVI and cataract surgical coverage remains essentially unchanged over the next 12 years. The number needing cataract surgery will increase by $43 \%$ to 0.6 million.

\section{Discussion}

The Nigeria National Blindness and Visual Impairment Survey used methods similar to those used in surveys coordinated by the same group in Bangladesh and Pakistan. ${ }^{17,18}$ Response rates were high in all GPZs which will have minimized nonresponse bias. ${ }^{15}$ The definitions used in the survey have been widely used in the past and therefore allow international comparisons to be made with earlier studies. ${ }^{17-19}$

Using the census data available in Nigeria we earlier estimated the magnitude of blindness among those $\geq 40$ years of age in Nigeria to be 1.13 million. ${ }^{15}$

However, the census data did not allow age standardization, as the age distribution for each decade was not provided for those $\geq 40$ years of age. We revised the estimates using population data provided by the U.S. Census Bureau which allows age standardization as well as future projections to be made for the year $2020 .{ }^{1}$ We estimate that the number of adults aged $\geq 40$ years with presenting vision $<6 / 60$ in the better eye will increase from 1.02 million in 2008 to 1.4 million in 2020.

For logistic reasons visual fields were only performed on a subsample and were not used to define blindness or visual impairment. This may have led to an underestimation of the prevalence of blindness due to glaucoma. Since the primary cause for some conditions such as phthisis or absent globe could not always be accurately determined, it is possible that some cases of avoidable blindness may have been misclassified as unavoidable. However, we feel that this proportion will be very small and unlikely to change the overall findings.

TABle 3. Association of Sociodemographic Factors and Prevalence of Common Causes of Presenting Vision $<6 / 60$ in the Better Eye

\begin{tabular}{|c|c|c|c|c|c|c|}
\hline Parameters & $\begin{array}{l}\text { Refractive } \\
\text { Errors }\end{array}$ & Cataract & Glaucoma & $\begin{array}{c}\text { Uncorrected } \\
\text { Aphakia }\end{array}$ & All Cornea & $\begin{array}{c}\text { All Posterior } \\
\text { Segment }\end{array}$ \\
\hline \multicolumn{7}{|l|}{ Age (y) } \\
\hline $40-49$ & $2(0.04)$ & $6(0.12)$ & $10(0.2)$ & $2(0.04)$ & $6(0.12)$ & $3(0.06)$ \\
\hline $50-59$ & $6(0.17)$ & $24(0.67)$ & $15(0.42)$ & $9(0.25)$ & $9(0.25)$ & $10(0.28)$ \\
\hline $60-69$ & $14(0.51)$ & $63(2.28)$ & $22(0.79)$ & $19(0.69)$ & $22(0.79)$ & $19(0.69)$ \\
\hline $70-79$ & $6(0.36)$ & $124(7.51)$ & $29(1.76)$ & $25(1.51)$ & $29(1.76)$ & $17(1.03)$ \\
\hline$\geq 80$ & $3(0.43)$ & $119(17.02)$ & $27(3.86)$ & $25(3.58)$ & $17(2.43)$ & $11(1.57)$ \\
\hline \multicolumn{7}{|l|}{ Sex } \\
\hline Female & $21(0.29)$ & 217 (2.96) & $32(0.44)$ & $39(0.53)$ & $42(0.57)$ & $38(0.52)$ \\
\hline Male & $10(0.16)$ & $119(1.91)$ & $71(1.14)$ & $41(0.66)$ & $41(0.66)$ & $22(0.35)$ \\
\hline \multicolumn{7}{|l|}{ Residence } \\
\hline Rural & $22(0.21)$ & 277 (2.63) & $78(0.74)$ & $61(0.58)$ & $70(0.66)$ & $44(0.42)$ \\
\hline Urban & $9(0.3)$ & $59(1.94)$ & $25(0.82)$ & $19(0.62)$ & $13(0.43)$ & $16(0.52)$ \\
\hline \multicolumn{7}{|l|}{ GPZ } \\
\hline North East & $4(0.23)$ & $65(3.76)$ & $16(0.93)$ & $16(0.93)$ & $20(1.16)$ & $2(0.12)$ \\
\hline South East & $3(0.18)$ & $55(3.32)$ & $19(1.15)$ & $8(0.48)$ & $2(0.12)$ & $15(0.9)$ \\
\hline South-South & $4(0.22)$ & $52(2.81)$ & $13(0.7)$ & $5(0.27)$ & $7(0.38)$ & $7(0.38)$ \\
\hline North West & $9(0.25)$ & $82(2.28)$ & $27(0.75)$ & $35(0.97)$ & $36(1.0)$ & $10(0.28)$ \\
\hline South West & $4(0.15)$ & $37(1.36)$ & $11(0.4)$ & $9(0.33)$ & $6(0.22)$ & $14(0.51)$ \\
\hline North Central & $7(0.35)$ & $45(2.22)$ & $17(0.84)$ & $7(0.35)$ & $12(0.59)$ & $12(0.59)$ \\
\hline \multicolumn{7}{|l|}{ Literacy } \\
\hline Illiterate & $28(0.37)$ & 283 (3.69) & $59(0.77)$ & $61(0.8)$ & $66(0.86)$ & $46(0.6)$ \\
\hline Literate & $3(0.05)$ & $53(0.89)$ & $44(0.74)$ & $19(0.32)$ & $17(0.29)$ & $14(0.24)$ \\
\hline
\end{tabular}

Data are the number of subjects (percentage of total group). 
Table 4. Age- and Sex-Adjusted Association of Principal Causes of Presenting Vision $<6 / 60$ in the Better Eye with Sociodemographic Factors

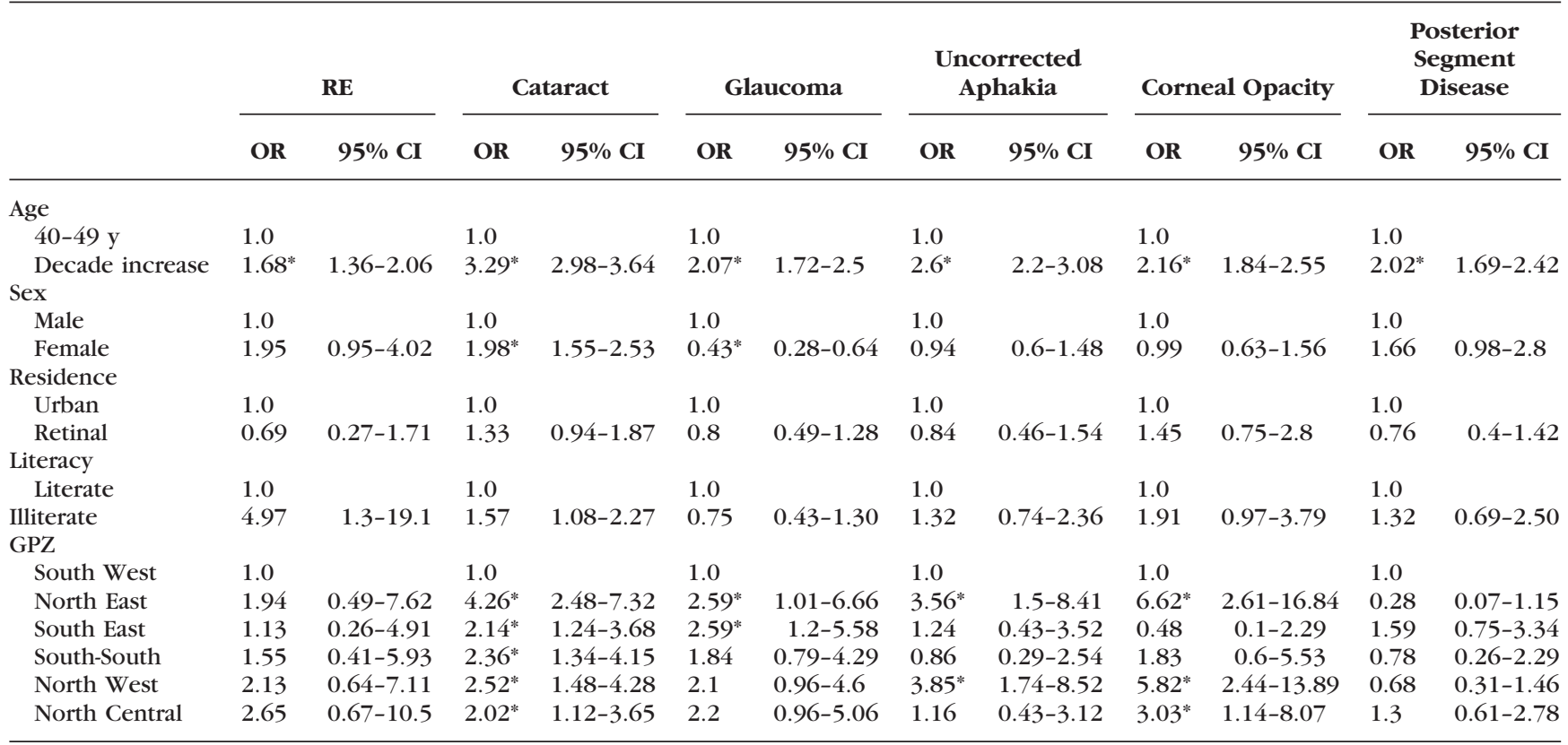

* Significant difference, $P<0.05$.

In Nigeria, $84 \%$ of all causes of blindness were either preventable or treatable. This is comparable to other reports from Nigeria, 6,10,12 and other countries in Africa such as Rwanda, ${ }^{24}$ Ghana, ${ }^{25}$ Sudan, ${ }^{26}$ Tunisia $^{27}$ Central African Republic, ${ }^{28}$ Niger, ${ }^{29}$ Cameroon, ${ }^{30}$ Kenya,${ }^{31}$ Ethiopia, ${ }^{32}$ and in South Asia (i.e., Bangladesh, ${ }^{18}$ Pakistan, ${ }^{17}$ and India $\left.{ }^{33}\right)$. However, most studies in Africa have been conducted on much smaller samples or in specific population groups. The exception is the national survey in Ethiopia, which is located on the eastern side of the African continent. All available evidence from different parts of Africa points to cataract being the single commonest cause of blindness and visual impairment (Table 6), but compared with many studies in South Asia, ${ }^{18,19,33}$ the proportion of blindness due to cataract is lower in Africa, ${ }^{24-32}$ perhaps due to a higher prevalence of glaucoma blindness and the presence of other blinding eye conditions that do not occur in Asia (e.g., onchocerciasis). If data were presented as cause-specific preva- lence rather than proportions any differences could be more easily interpreted.

The difference in the prevalence of vision loss due to cataract between men and women, urban and rural areas, and levels of education in Nigeria almost certainly reflects access to services.

Previous surveys in Nigeria ${ }^{34,35}$ and other locations in Afri$\mathrm{ca}^{26,32,36}$ have shown trachoma to be responsible for a significant proportion of blindness in certain areas. However, all these surveys, apart from the national survey in Ethiopia, ${ }^{32}$ were undertaken in trachoma endemic areas. The present survey included clusters in northern Nigeria where trachoma was known to be endemic, ${ }^{34,35}$ but even in these areas, trachoma was not a significant cause of vision loss. Local surveys in trachoma endemic areas can be used to identify foci with high endemicity and high levels of vision loss. Local surveys, because they are small and hence relatively inexpensive, can

Table 5. Age- and Sex-Standardized Estimated Number of Adults ( $\geq 40$ y) in Nigeria, According to Presenting VI

\begin{tabular}{|c|c|c|c|c|c|c|c|c|}
\hline \multirow[b]{2}{*}{ Cause } & \multicolumn{4}{|c|}{ Presenting Vision <6/12-6/60 (Mild/Moderate VI) } & \multicolumn{4}{|c|}{ Presenting Vision < 6/60 (SVI and Blindness) } \\
\hline & $\begin{array}{c}\text { Crude } \\
\text { Prevalence } \\
(\%)\end{array}$ & $\begin{array}{c}\text { Standardized } \\
\text { Prevalence } \\
(\%)^{*}\end{array}$ & $\begin{array}{c}2008 \\
\text { Estimated } \\
\text { Number }\end{array}$ & $\begin{array}{c}2020 \\
\text { Estimated } \\
\text { Number }\end{array}$ & $\begin{array}{c}\text { Crude } \\
\text { Prevalence } \\
(\%)\end{array}$ & $\begin{array}{c}\text { Standardized } \\
\text { Prevalence } \\
(\%)^{*}\end{array}$ & $\begin{array}{c}2008 \\
\text { Estimated } \\
\text { Number }\end{array}$ & $\begin{array}{c}2020 \\
\text { Estimated } \\
\text { Number }\end{array}$ \\
\hline Cataract & 3.48 & 2.39 & 630,624 & 878,209 & 2.47 & 1.51 & 399,041 & 570,512 \\
\hline Glaucoma & 0.28 & 0.21 & 56,620 & 79,159 & 0.76 & 0.56 & 147,064 & 205,266 \\
\hline Uncorrected aphakia & 0.38 & 0.29 & 75,711 & 105,026 & 0.59 & 0.38 & 101,425 & 142,048 \\
\hline Refractive error & 11.45 & 9.33 & $2,463,695$ & $3,400,953$ & 0.23 & 0.19 & 49,292 & 67,317 \\
\hline \multicolumn{9}{|l|}{$\begin{array}{l}\text { Central corneal opacity } \\
\text { (excluding }\end{array}$} \\
\hline trachoma) & 0.21 & 0.18 & 47,628 & 65,871 & 0.40 & 0.31 & 81,191 & 112,945 \\
\hline Trachoma & 0.13 & 0.12 & 30,441 & 40,615 & 0.19 & 0.13 & 33,424 & 47,146 \\
\hline \multicolumn{9}{|l|}{ Posterior segment } \\
\hline disease & 0.68 & 0.52 & 138,281 & 190,949 & 0.43 & 0.33 & 86,549 & 120,979 \\
\hline Onchocerciasis & 0.02 & 0.03 & 6,616 & 9,035 & 0.04 & 0.04 & 9,611 & 12,719 \\
\hline Other & 0.73 & 0.56 & 147,936 & 205,178 & 0.55 & 0.45 & 117,718 & 163,622 \\
\hline Total & 17.36 & 13.62 & $3,597,552$ & $4,974,995$ & 5.68 & 3.88 & $1,025,315$ & $1,442,554$ \\
\hline
\end{tabular}

${ }^{*}$ Age and sex standardization using Nigeria's population for 2008 and projection for $2020 .^{1}$ 
TABLE 6. Major Causes of Blindness in Population-Based Studies in Africa and South Asia

\begin{tabular}{|c|c|c|c|c|c|c|c|}
\hline Country & Level & Age Covered & Examined & Year & $\mathbf{V A}$ & Cause $1(\%)$ & Cause $2(\%)$ \\
\hline Ethiopia $^{32}$ & National & All ages & 25,650 & 2006 & $<3 / 60$ & Cataract (49.9) & Trachoma (11.5) \\
\hline Nigeria $^{5}$ & Local & All ages & 1,248 & 2005 & $<3 / 60$ & Cataract $(57,2)$ & Glaucoma (14.3) \\
\hline Rwanda ${ }^{24}$ & Local & $\geq 50 y$ & 2,206 & 2005 & $<3 / 60$ & Cataract (65) & Posterior segment (20) \\
\hline Cameroon $^{30}$ & Local & $\geq 40 y$ & 2,215 & 2006 & $<3 / 60$ & Posterior segment (29) & Cataract (21) \\
\hline Ghana $^{25}$ & Local & $\geq 40 y$ & 2,298 & 2003 & $<3 / 60$ & Cataract (53.9) & Glaucoma (20.6) \\
\hline Sudan $^{26}$ & Local & $\geq 5 y$ & 2,499 & 2005 & $<3 / 60$ & Cataract (41.2) & Trachoma (35.3) \\
\hline Kenya $^{31}$ & Local & $\geq 50 \mathrm{y}$ & 3,503 & 2005 & $<3 / 60$ & Cataract (42) & Posterior segment (30.4) \\
\hline Bangladesh $^{18}$ & National & $\geq 30 \mathrm{y}$ & 11,624 & 2002 & $<3 / 60$ & Cataract (79.6) & Uncorrected aphakia (6.2) \\
\hline Pakistan $^{17}$ & National & $\geq 30 y$ & 16,507 & 2004 & $<3 / 60$ & Cataract (51.5) & Corneal opacity (11.8) \\
\hline India ${ }^{19}$ & National & $\geq 50 \mathrm{y}$ & 63,337 & 2001 & $<6 / 60$ & Cataract (62.4) & Refractive errors (19.6) \\
\hline India $^{33}$ & National & $\geq 50 y$ & 40,447 & 2007 & $<3 / 60$ & Cataract (72.2) & Corneal opacity (5.9) \\
\hline Nigeria (present study) & National & $\geq 40 y$ & 13,599 & 2006 & $<3 / 60$ & Cataract (43.0) & Glaucoma (16.7) \\
\hline
\end{tabular}

be repeated, thus providing a mechanism for monitoring change in prevalence of disease and visual impairment over time. The sampling method used in the Nigeria national survey may well have led to an underestimation of vision loss due to trachoma in endemic areas, but the findings overall are of value for priority-setting at a national level.

Onchocerciasis was also not a significant cause of blindness in our survey, despite the fact that the sample included clusters from areas where onchocerciasis has been known to be endemic. Earlier surveys showed that onchocerciasis is an important cause of blindness in endemic areas of Africa, including Nigeria, ${ }^{10,11,28,37-39}$ and ocular manifestations of onchocerciasis have been recorded in the savannah as well as in the rain forest areas. ${ }^{40,41}$ There are several possible explanations for our findings: First, both onchocerciasis and trachoma are focal diseases, and the clusters selected even in endemic areas may, by chance, have not included areas with the highest endemicity. Second, there may have been misclassification: For example, corneal scarring from trachoma may have been misclassified as nontrachomatous, but this seems unlikely, and corneal opacity, chorioretinitis and optic atrophy may not have been attributed to onchocercaisis. Third, the findings may reflect a genuine decline in blindness from these two diseases, particularly that due to onchocerciasis as a consequence of the Africa Onchocerciasis Control Programme (APOC). ${ }^{42-44}$

Despite its size, there has been no earlier national estimate of the prevalence and causes of blindness and visual impairment in Nigeria. Data from surveys of special groups or in focal areas cannot be extrapolated to the entire country, because of its cultural, economic, ethnic and geographical diversity. Data from the national survey will provide evidence for policy formulation and strategic planning at the national level and monitoring progress toward achievement of goals of VISION2020: The Right to Sight Initiative. Effective implementation of programs at regional and district levels also needs evidence and the survey provides precise estimates at the regional level. The data can also be used by the World Health Organization, Ministries of Health, and international nongovernmental organizations in planning, implementing, and monitoring eye care programs in similar geoeconomic areas in 19 other countries in West and Central Africa, where data do not already exist.

The evidence now available for Nigeria shows that a significant proportion of those with mild and moderate visual impairment can immediately benefit from optical and refraction services, whereas most of those with SVI or blindness are in need of cataract surgery. VISION2020 emphasizes the need to strengthen both services if the elimination of avoidable blindness is to become a reality. ${ }^{45}$

With $80 \%$ of blindness being avoidable and the success of approaches like cataract surgery being established, effective implementation of VISION2020 may contribute toward devel- opment and economic productivity. Special efforts are needed to target women, persons living in rural areas, and persons who are poorly educated. Regional variations need to be addressed so that priority attention is given to those regions/ zones that have high magnitude and lack adequate surgical or optical services within a system that delivers comprehensive eye care to populations.

\section{Acknowledgments}

The authors thank Oye Quaye for managing the finances for the study; Auwal Shehu and Dania Charles for data entry; and the teams of ophthalmic nurses, enumerators, and interviewers in the six geopolitical zones who assisted in data collection.

\section{References}

1. U.S. Census Bureau. International Data Base (IDB). http://www. census.gov/cgi-bin/ipc/idbrank.pl/ Accessed March 9, 2009.

2. United Nations Development Program. http://hdrstats.undp.org/ 2008/countries/ country_fact_sheets/cty_fs_NGA.html. Accessed December 19, 2008.

3. Central Intelligence Agency. The World Fact book. https://www. cia.gov/library/publications/the-world-factbook/geos/ni.html. Accessed December 19, 2008.

4. Resnikoff S, Pascolini D, Etya'ale D, et al. Global data on visual impairment in the year 2002. Bull World Health Org. 2004;82: $844-851$.

5. Onokpoya OH, Adeoye AO, Akinsola FB, Adegbehingbe BO. Prevalence of blindness and visual impairment in Atakunmosa West Local Government area of south-western Nigeria. Tanzan Health Res Bull. 2007;9:126-131.

6. Adegbehingbe BO, Majengbasan TO. Ocular health status of rural dwellers in south-western Nigeria. Aust J Rural Health. 2007;15: 269-272.

7. Rabiu MM. Cataract blindness and barriers to uptake of cataract surgery in a rural community of northern Nigeria. $\mathrm{Br} J$ Opbthalmol. 2001;85:776-780.

8. Ezepue UF. Magnitude and causes of blindness and low vision in Anambra state of Nigeria (results of 1992 point prevalence survey). Public Health. 1997;111:305-309.

9. Adeoye A. Survey of blindness in rural communities of south western Nigeria. Trop Med Int Health. 1996;1:672-676.

10. Abiose A, Murdoch I, Babalola O, et al. Distribution and aetiology of blindness and visual impairment in mesoendemic onchocercal communities, Kaduna State, Nigeria. Br J Opbthalmol. 1994;78:8 13.

11. Patrick-Ferife G, Ashaye AO, Qureshi BM. Blindness and low vision in adults in Ozoro, a rural community in Delta State, Nigeria., Niger J Med. 2005;14:390-395.

12. Abdu L. Prevalence and causes of blindness and low vision in Dambatta local government area, Kano State, Nigeria. Niger J Med. 2002;11:108-112. 
13. World Health Organization. VISION2020: The Right to Sight Global Initiative for the Elimination of Avoidable Blindness: Action Plan 2006-2011.World Health Organization, Geneva, Switzerland; 2007;1-97.

14. Dineen B, Gilbert CE, Rabiu MM, et al. The Nigerian national blindness and visual impairment survey: rationale, objectives and detailed methodology. BMC Ophthalmol. 2008;8:17.

15. Kyari F, Murthy GVS, Sivasubramaniam S, et al. Prevalence of blindness and visual impairment in Nigeria: the Nigeria national blindness and visual impairment survey. Invest Ophthalmol Vis Sci. 200950:2033-2039.

16. http://www.who.int/blindness/ Change\%20the\%20Definition\%20of\%20Blindness.pdf. Accessed December 19, 2008.

17. Jadoon MZ, Dineen B, Bourne RRA, et al. Prevalence of blindness and visual impairment in pakistan: The Pakistan National Blindness and Visual Impairment Survey. Invest Ophthalmol Vis Sci. 2006; 47:4749- 4755 .

18. Dineen BP, Bourne RRA, Ali SM, Huq DMN, Johnson GJ. Prevalence and causes of blindness and visual impairment in Bangladeshi adults: results of the National Blindness and Low Vision Survey of Bangladesh. Br J Ophthalmol. 2003;87:820 - 828.

19. Murthy GVS, Gupta SK, Bachani D, Jose R, John N. Current estimates of blindness in India. Br J Ophthalmol. 2005;89:257-260.

20. Bourne RR, Rosser DA, Sukudom P, et al. Evaluating a new logMAR chart designed to improve visual acuity assessment in population based surveys. Eye. 2003;17:754-758.

21. World Health Organization. Coding Instructions for the WHO/PBL Eye Examination Record (version III). PBL/88.1. Geneva: WHO; 1988.

22. Mehra V, Minassian DC. A rapid method of grading cataract in epidemiological studies and eye surveys. Br J Ophthalmol. 1988; 72:801-803.

23. Thylefors B, Chylack LT Jr, Konayama K, et al. A simplified cataract grading system. Ophthalmic Epidemiol. 2002;9:83-95.

24. Mathenge W, Nkurukiye J, Limburg H, Kuper H. Rapid assessment of avoidable blindness in Western Rwanda: blindness in a post conflict setting. PLoS Med. 2007;4:e217.

25. Guzek JP, Anyomi FK, Fiadoyor S, Nyonator F. Prevalence of blindness in people over 40 years in the Volta region of Ghana. Ghana Med J. 2005;39:55-62.

26. Ngondi J, Ole-Sempele F, Onsarigo A, et al. Prevalence and causes of blindness and low vision in southern Sudan. PLoS Med. 2006; 3:e477.

27. Ayed S, Negrel AD, Nabli M, Kamel M, Jebri AM, Siddhom M. Prevalence and causes of blindness in the Tunisian Republic: results of a national survey conducted in 1993. Sante. 1998;8:275282.

28. Schartwz EC, Huss R, Hopkins A, et al. Blindness and visual impairment in a region endemic for onchocerciasis in the Central African Republic. Br J Ophthalmol. 1997;81:443-447.

29. Kabo AM. Prevalence of blindness in Niger (in French). Rev Int Trach Pathol Ocul Trop Subtrop Sante Publique. 1989;66:55-62.

30. Oye JE, Kupfer H. Prevalence and causes of blindness and visual impairment in Limbe urban area, South West province, Cameroon. Br J Ophthalmol. 2007;91:1435-1439.
31. Mathenge W, Kuper H, Limburg H, et al. Rapid assessment of avoidable blindness in Nakuru district, Kenya. Ophthalmology. 2007;114:599-605.

32. Berhane Y, Worku A, Bejiga A, et al. Prevalence and causes of blindness and low vision in Ethiopia. Ethiop J Health Dev. 2007; 21:204-210.

33. John N, Jose R, Vashist P, Murthy GV, RAAB India Study Group. Rapid assessment of avoidable blindness in India. PLOS ONE. 2008; 3:e2867.

34. Mpyet C, Ogoshi C, Goyol M. Prevalence of trachoma in Yobe State, north eastern Nigeria. Ophthalmic Epidemiol. 2008;15:303307 .

35. Mansur R, Muhammad N, Liman IR. Prevalence and magnitude of trachoma in a local government area of Sokoto State, north western Nigeria. Niger J Med. 2007;16:348-353.

36. Alemayehu W, Tekle-Haimanot R, Forsgren L, Erkstedt J. Causes of visual impairment in central Ethiopia. Ethiop Med J. 1995;33:163174 .

37. Umeh RE, Chijioke CP, Okonkwo PO. Eye diseases in an onchocerciasis-endemic area of the forest-savannah mosaic region of Nigeria. Bull World Health Organ. 1996;74:95-100.

38. Moll AC, van der Linden AJ, Hogeweg M, Schader WE, Hermans J, de Keizer RJ. Prevalence of blindness and low vision of people over 30 years of age in the Wenchi district, Ghana, in relation to eye care programmes. Br J Ophthalmol. 1994;78:275-279.

39. Whitworth JA, Gilbert CE, Mabey DM, Morgan D, Foster A. Visual loss on an onchocerciasis-endemic community in Sierra Leone. Br J Ophthalmol. 1993;77:30-32.

40. Cooper PJ, Proano R, Beltran C, Anselmi M, Guderian RH. Onchocerciasis in Ecuador: ocular findings in Oncocerca volvulus infected individuals. Br J Ophthalmol. 1995;79:157-162.

41. Somo RM, Enyong PA, Fobi G, et al. A study of onchocerciasis with severe skin and eye lesions in a hyperendemic zone in the forest of south-western Cameroon: clinical, parasitologic and entomologic findings. Am J Trop Med Hyg. 1993;48:14-19.

42. Tielsch JM, Beeche A. Impact of ivermectin on illness and disability associated with onchocerciasis. Trop Med Int Health. 2004;9:A45A56.

43. Little MP, Basanez M-G, Breitling LP, Boatin BA, Alley ES. Incidence of blindness during the Onchocerciasis Control Programme in Western Africa 1971-2002. J Infectious Dis. 2004;189:1932-1941.

44. Hadad D, Cross C, Thylefors B, et al. Health care at the end of the road: opportunities from 20 years of partnership in onchocerciasis control. Global Public Health. 2008;3:187-196.

45. Thylefors B. A global initiative for the elimination of avoidable blindness. Community Eye Health. 1998;11:1-3.

\section{APPENDix}

\section{The Nigeria National Blindness and Visual Impairment Study Group}

Adenike Abiose, Abdulla Usman Imam, Bankole Olufunmilayo O, Fatima Kyari, Gabriel Entekume, Hannah Faal, and Pak Sang Lee, in addition to the other authors of the article. 